\title{
Application of capillary electrophoresis coupling with electrochemiluminescence detection to estimate activity of butyrylcholinesterase
}

\author{
Dongdong Wang, Fanlin Li, Ming Su, Hanwen Sun \\ College of Chemistry and Environmental Science, Hebei University, Key Laboratory of Analytical Science and Technology of Hebei Province, Baoding, \\ 071002, China.
}

\section{ARTICLE INFO \\ Article history: \\ Received on: 08/03/2016 \\ Accepted on: 07/04/2017 \\ Available online: 29/04/2018}

\section{Key words:}

Capillary electrophoresis,

electrochemiluminescence, butyrylcholinesterase,

enzyme activity.

\begin{abstract}
A new method to estimate the butyrylcholinesterase (BChE, EC 3.1.1.8) activity by using capillary electrophoresis (CE) coupled with electrochemiluminescence (ECL) is described. The liberated N,N-dimethylethanolamine (DMEA) that is produced by $\mathrm{BChE}$ catalyzed hydrolysis reaction of tetracine hydrochloride was used as ECL coreagent to enhance $\mathrm{Ru}(\mathrm{bpy}){ }_{3}{ }^{2+} \mathrm{ECL}$ signals efficiently. The detection limit for DMEA was $1.98 \times 10^{-8} \mathrm{M}(\mathrm{S} / \mathrm{N}=3)$, which is equal to $6.6 \times 10^{-10}$ units of $\mathrm{BChE}$ used to catalyze substrate for 30 mins. The Michaelis constant $K_{\mathrm{m}}\left(1.16 \times 10^{-3}\right.$ $\mathrm{mol} / \mathrm{L})$ and the maximum reaction velocity $V_{\text {max }}\left(2.71 \times 10^{-7} \mathrm{~mol} / \mathrm{L} / \mathrm{min}\right)$ of $\mathrm{BChE}$ for tetracine hydrochloride are determined. Also, the reaction conditions including the concentration of metal ions, incubation temperature and $\mathrm{pH}$ were optimized. This method was successfully applied to detect $\mathrm{BChE}$ activity as a bio-marker in plasma and the results were in good agreement with that obtained by the clinical method.
\end{abstract}

\section{INTRODUCTION}

Butyrylcholinesterase (EC 3.1.1.8; BChE), also known as pseudocholinesterase, is a serine hydrolase with $\alpha / \beta$ hydrolase fold that hydrolyzes chemicals containing ester bonds (Fogle et al., 2016). The BChE has unique enzymatic properties and is widely distributed in almost all mammalian tissues, such as kidneys, intestine, lung and central nervous system, also localized on the red blood cell surface (Gorelick, 1997; Gómez et al., 2000). However, the $440 \mathrm{KDa}$ tetrameric glycoprotein is mainly synthesized in the liver and is released into plasma immediately upon synthesis (Saxena et al., 1997). Usually, the enzyme is found predominantly in plasma (Carmona et al., 2000; Peters et al., 2012). The BChE has a few known functions in the body, and it is thought to be primarily

${ }^{*}$ Corresponding Author

Ming Su, College of Chemistry and Environmental Science, Hebei University, Key Laboratory of Analytical Science and Technology of Hebei Province, Baoding, 071002, China.E-mail: suminghbu@126.com responsible for detoxification reactions in the serum, liver, lungs, and intestinal mucosa, mainly acting as an endogenous bioscavenger for defensing against toxic compounds reaching the bloodstream (Ashani, 2000). A deficiency of BChE can result in delayed metabolism of various drugs, such as cocaine (Lynch et al., 1997), and treatment with doses of BChE can help in overcoming the physiological reaction to them. Moreover, as an activator enzyme, BChE converts administered prodrugs into functional therapeutics. However, the exact physiological function of BChE remains elusive (Johnson and Moore, 2012). According to the literature, the number of $\mathrm{BChE}$ molecules is about ten times more than the number of AChE which is a sister enzyme essential for functioning of the nervous system in the human body, BChE represents $0.1 \%$ of human plasma proteins with its concentration of 2-5 mg/L (Manoharan et al., 2007; Brimijoin and Hammond, 1988). So, the BChE is also called "plasma cholinesterase" and is generally used in reference to a clinical test that reflects levels of this enzyme in the blood (Peters et al., 2012). Clinical and laboratory blood test for the monitoring of butyrylcholinesterase activity in plasma can be 
used as a liver function test (Buetis, 1999). The alterations of its activity have been associated with several pathological disorders of inflammatory disease (Tvarijonaviciute et al., 2013), liver injury (Blanloeil and Delaroche, 1996), including hepatitis, cirrhosis and hepatic carcinoma, and its inhibition is taken as a biomarker for indicating pathological processes.

So far, the spectrophotometric method of Ellman is widely used to estimate butyrylcholinesterase activity (Waiskopf et al., 2011; Lucić et al., 2005; Ellman et al., 1961), using acetylthiocholine or butyrylthiocholine iodide as substrate. In this assay, the thiocholine that is produced enzymatically is coupled with Ellman's reagent to produce a coloured azo complex, whose absorbance is measured at $412 \mathrm{~nm}$ by UV-Visible spectrophotometry. The absorption intensity is proportional to the activity of BChE. However, the chromogenic reagent has poor chemical stability, enormous toxicity, carcinogenicity, and the sensitivity of UV detection is also limited.
CE in combination with ECL had been widely used, and mainly focused on the amine analysis ( $\mathrm{Li}$ and Lee, 2007; Sreedhar et al., 2005), drug analysis (Deng et al., 2011; Yuan et al., 2010), monitoring the metabolism of drugs (Liu et al., 2010; Wang et al., 2011). However, only a few papers ( $\mathrm{Li}$ et al., 2006; Yuan et al., 2006; Yuan et al., 2007; Su et al., 2013) about determination of bioactive enzymes using CE-ECL have been published. Herein, the CE-ECL method was successfully applied to detect $\mathrm{BChE}$ activity. Considering that $\mathrm{BChE}$ has high catalytic activity on ester bonds and is clinically important because of hydrolysis of the ester-type local anaesthetics, tetracine hydrochloride, containing both ester bond and a tertiary amine functional groups was chosen as a substrate for the enzyme catalyzed reactions. During the incubation procedure tetracine hydrochloride was hydrolyzed by the action of $\mathrm{BChE}$, as shown in Fig. 1.

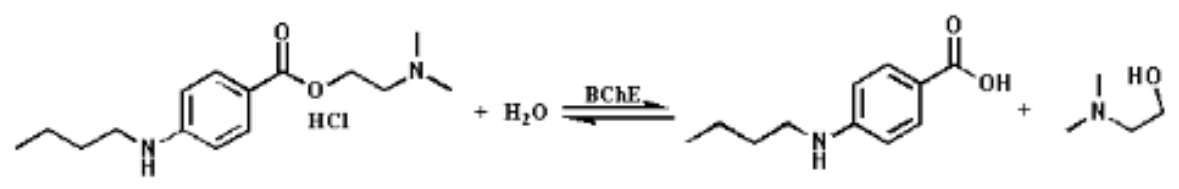

4-(n-Butylam ino)benzoic acid

T etr ac aine Hydrochloride

$\mathrm{N}, \mathrm{N}$-Dim ethylethanolamine

Fig. 1: Catalytic reaction of tetracine hydrochloride by butyrylcholinesterase(BChE).

Since the ECL signals of 4-(n-Butylamino)benzoic acid molecule are negligible, luminescent quantification of the enzymatic reaction will depend on the depletion of tetracine hydrochloride or the production of DMEA molecules. Finally, DMEA was chosen as quantitative probe because it enhanced $\mathrm{Ru}(\mathrm{bpy})_{3}{ }^{2+} \mathrm{ECL}$ response significantly than tetracine hydrochloride. Several factors such as metal ions, $\mathrm{pH}$, incubation temperature and time on the enzymatic catalysis reaction against tetracine hydrochloride were studied. $K_{\mathrm{m}}$ and $V_{\max }$ of $\mathrm{BChE}$ for tetracine hydrochloride were also studied. Monitoring of plasma butyrylcholinesterase should be recommended for patients with liver tissue injury as this may be a useful biomarker to predict and prevent health hazards of liver disease. The method was successfully used to assay BChE activity in plasma. Therefore this method can be used in the clinical diagnosis of relevant diseases.

\section{MATERIALS AND METHODS}

\section{Chemicals and reagents}

All reagents used were of analytical grade. Doubledistilled water was used throughout the study. Tris(2,2'-bipyridyl) ruthenium(II) chloride hexahydrate ( $\mathrm{Ru}\left(\right.$ bpy) $\left.{ }_{3} \mathrm{Cl}_{2} \cdot 6 \mathrm{H}_{2} \mathrm{O}, 99.95 \%\right)$, tetracine hydrochloride (99.5\%), N,N-dimethylethanolamine $(99.5 \%)$ were purchased from Sigma-Aldrich Co. (St. Louis, MO, USA). Butyrylcholinesterase (10 untis/mg protein, from equine serm EC 3.1.1.8) was also from Sigma-Aldrich Co. and was stored at $-20^{\circ} \mathrm{C}$. Enzyme standard solutions were prepared and diluted with phosphate buffer solution (PBS). The blank plasma samples of healthy people and patients as gifts were collected from the Affiliated Hospital of Hebei University (Baoding, China). Deionized water with conductivity less than $1.0 \mu \mathrm{S} \mathrm{cm}^{-1}$ was used for sample dilution and reagent preparation. Other chemicals were of analytical grade and used as received.

\section{Apparatus}

All separation and detection were done on a Model MPI-B Multi parameter chemiluminescence analyzer systems (Xi'an Remax Electronic High-Tech Ltd, Xi'an, China). A programmable high-voltage power supply $(0-20 \mathrm{kV})$ was applied to drive the electrokinetic sample injection and electrophoretic separation. All data were accomplished with a multifunctional chemiluminescence analyzer, an electrochemical and electrochemiluminescent spectrums were obtained by the MPI-B analysis software. The end-column ECL detection was installed with a three-electrode configuration, which was made up of $500 \mu \mathrm{m}$ platinum disk electrode as working electrode, a platinum wire as counter electrode and $\mathrm{Ag} / \mathrm{AgCl}(1.0 \mathrm{M}$ $\mathrm{KCl}$ saturated by $\mathrm{AgCl}$ ) electrode as reference electrode. An uncoated fused silica capillary with $40 \mathrm{~cm}$ length, $25 \mu \mathrm{m}$ i.d. and $360 \mu \mathrm{m}$ o.d. was used for separation (Yongnian Ruipu chromatogram equipment Ltd, Hebei, China). Amicon Ultra $0.5 \mathrm{~mL}$ centrifugal filters with MWCO $10 \mathrm{kDa}$ were purchased from Millipore Corporation. 


\section{CE-ECL analysis}

The new capillary was filled with $0.1 \mathrm{M}$ sodium hydroxide over night before use. Prior to starting a series of analyses, the capillary was washed with $1.0 \mathrm{M}$ sodium hydroxide for $5 \mathrm{~min}$, followed by double distilled water for $5 \mathrm{~min}$, and equilibrated with the running buffer for $5 \mathrm{~min}$ to maintain an active and reproducible inner surface. A solution of $5 \mathrm{mM} \mathrm{Ru}(\mathrm{bpy})_{3}{ }^{2+}$ in $80 \mathrm{mM}$ phosphate buffer ( $\mathrm{pH} 7.0)$ was directly injected into the detection reservoir, and the solution in the cell was replaced every $2 \mathrm{~h}$ in order to obtain good repeatability. The ECL signal was recorded by the MPI-B system. The input voltage of the photomultiplier tube was set at $800 \mathrm{~V}$. Samples were injected in an electrokinetic mode at $10 \mathrm{kV}$ for $10 \mathrm{~s}$, separated in the capillary at $15 \mathrm{kV}$. Sample injections were made at the cathodic side of the capillary. Prior to CE analysis, the required sample solutions and PBS were filtered through $0.22 \mu \mathrm{m}$ cellulose acetate membrane filters (Shanghai Xinya Purification Material Factory, Shanghai, China).

\section{Enzyme catalyzed reaction}

A $10 \mu \mathrm{L}$ enzyme sample $(2.1 \mathrm{U})$ was mixed with metal ions and tetracine hydrochloride, and then the mixture was incubated at a constant temperature, $37^{\circ} \mathrm{C}$ for $30 \mathrm{mins}$. Although the enzyme reaction could be terminated by heating several minutes in boiling water, however, high temperatures can accelerate the hydrolysis of tetracine hydrochloride. So the transamination reaction was terminated by adjusting $\mathrm{pH}$ to 2.0 with $1.0 \mathrm{M} \mathrm{HCl}$ based on the protein acidic denaturalization in these experiments. Finally, the hydrolyzed products were transferred into Amicon Ultra filter device and centrifuged at $8000 \mathrm{rpm}$ for $5 \mathrm{mins}$. The ultrafiltrate was diluted five-fold with phosphate buffer and then electrokinetically injected for CE-ECL measurements. Controls containing only substrate indicated that the assay buffer did not induce substrate hydrolysis. The unit of $\mathrm{BChE}$ activity used in this paper was unit per liter (U/L), which was defined as the amounts of enzyme that hydrolyzed $1.0 \mu \mathrm{M}$ of tetracine hydrochloride per $\min$ at $37^{\circ} \mathrm{C}$. The hydrolysis of the substrate was monitored by detecting ECL intensity of DMEA.

\section{Preparation of blood sample}

Anticoagulant such as potassium oxalate, sodium citrate, or the disodium salt of ethylenediamine tetraacetate dihydrate always inhibited $\mathrm{BChE}$ activity. So, heparinized plasma was used in our experiment. About $2 \mathrm{~mL}$ of anticoagulant human whole blood samples were collected in a $5 \mathrm{~mL}$ centrifuge tube and centrifuged at $3000 \mathrm{rpm}$ for $10 \mathrm{mins}$. The supernatants (the plasma) were then collected in a $1.5 \mathrm{~mL}$ microcentrifuge tube, stored at $-20^{\circ} \mathrm{C}$ until use. They were diluted to 10 -fold before $\mathrm{CE}$ analysis.

\section{RESULTS AND DISCUSSION}

\section{Detection of standard DMEA}

DMEA can enhance the Ru(bpy) ${ }_{3}{ }^{2+}$ ECL efficiently. The ECL intensity of $\mathrm{Ru}(\mathrm{bpy})_{3}{ }^{2+} / \mathrm{DMEA}$ system was $\mathrm{pH}$ dependant and the optimum $\mathrm{pH}$ was found at $\mathrm{pH} 8.0$ which agreed with the reported optimal $\mathrm{pH}$ range 6-9 for ECL reactions between $\mathrm{Ru}$ (bpy) ${ }_{3}^{2+}$ and amines. On the other hand, $80 \mathrm{mM} \mathrm{pH} 7.0$ PBS was used as the ECL detection buffer to offset possible $\mathrm{pH}$ change caused by the $\mathrm{CE}$ running buffer. Under the optimized conditions: ECL detection at $1.2 \mathrm{~V}$, separation voltage at 15 $\mathrm{kV}, 30 \mathrm{mM}$ PBS running buffer at $\mathrm{pH} 8.0,5 \mathrm{mM} \mathrm{Ru}(\mathrm{bpy})_{3}{ }^{2+}$ dissolved in $80 \mathrm{mM}$ PBS at $\mathrm{pH} 7.0$ in the detection reservoir, the electrokinetical injection for $10 \mathrm{~s}$ at $10 \mathrm{kV}$, the linear range for DMEA extended from $3 \times 10^{-8}$ to $6.6 \times 10^{-7} \mathrm{M}$ and from $1.6 \times 10^{-6}$ to $6.4 \times 10^{-5} \mathrm{M}$. The calibration curve equation was $\mathrm{Y}=(1.6 \mathrm{E}+3) \mathrm{X}-31.6793(\mathrm{R}=0.9990)$ and $\mathrm{Y}=-21526.8 \lg \mathrm{X}$ $+21772(\mathrm{R}=0.9971)$, where $\mathrm{X}(\mathrm{M})$ and $\mathrm{Y}$ stood for the concentration of DMEA and the corresponding ECL intensity respectively. The detection limit of DMEA was $1.98 \times 10^{-8} \mathrm{M}$ $(\mathrm{S} / \mathrm{N}=3)$, corresponding to $6.6 \times 10^{-10} \mathrm{U} / \mathrm{L}\left(9.43 \times 10^{-3} \mu \mathrm{g} /\right.$ $\mathrm{mL}$ ) of BChE catalyzing tetracine hydrochloride for $1 \mathrm{~min}$. So, the corresponding LOD of BChE was $9.43 \times 10^{-3} \mu \mathrm{g} / \mathrm{mL}$ in this method. $0.1 \mu \mathrm{M}$ and 1.0 $\mu \mathrm{M}$ DMEA was injected consecutively six times to determine the repeatability of ECL intensity and migration time. Relative standard derivations of them were $3.5 \%$ and $1.2 \%, 3.0 \%$ and $0.3 \%$ respectively.

\section{The activation of metal ions as cofactors on $\mathrm{BChE}$}

Usually, the $\mathrm{BChE}$ was fully activated by $\mathrm{Ca}^{2+}$ and $\mathrm{Mg}^{2+}$. Metal ions played an important role in substrate binding. Thus, type of metal ion at the active site of $\mathrm{BChE}$ influenced enzymatic activity. The concentration effect of $\mathrm{Ca}^{2+}$ and $\mathrm{Mg}^{2+}$ on $\mathrm{BChE}$ activity against tetracine hydrochloride was investigated. As shown in Fig. 2 , the enzyme was strongly activated by both $\mathrm{Ca}^{2+}$ and $\mathrm{Mg}^{2+}$. At the low concentration, $\mathrm{BChE}$ activity increased with increasing concentration of both metal ions. $\mathrm{BChE}$ reached its highest activity at $2.0 \mathrm{mM} \mathrm{Ca}^{2+}$ and $1.2 \mathrm{mM} \mathrm{Mg}^{2+}$ respectively and decreased if the concentration of the metal ions further increased. Compared to $\mathrm{Mg}^{2+}, \mathrm{Ca}^{2+}$ strongly stimulated enzymatic activity to 1.6 times under the optimized conditions. So, $2.0 \mathrm{mM} \mathrm{Ca}^{2+}$ was chosen in our experiments hereafter. Although $\mathrm{Ca}^{2+}$ stimulated $\mathrm{BChE}$ activity at concentrations between 0.4 and $2.0 \mathrm{mM}$, it inhibited the enzyme activity at higher concentrations. The reason is that excess amount of $\mathrm{Ca}^{2+}$ may change the conformation of its metal binding site. Based on inhibition of zinc ions on aminopeptidase (Auld, 2004), we propose that metal ions bind to the groups that have negative charges, such as the carboxyl gourp of the "Ser198His438-Glu325" catalytic triad in the esteratic site, or Asp-70 in the peripheral anionic site of human butyrylcholinesterase, which reduce the charge on the metal, making it more difficult for the metal-bound water to ionize and for the metal to act as a Lewis acid catalyst.

\section{Effect of pH on BChE activity}

The BChE activity between $\mathrm{pH} 4.0$ and 8.0 was determined in the presence of $2.0 \mathrm{mM} \mathrm{Ca}^{2+}$ and $1.0 \mathrm{mM}$ tetracine hydrochloride. Fig.3 showed that the optimum pH was 7.5 The enzyme was relatively stable between $\mathrm{pH} 7.0$ and 7.8 and lost activity rapidly when the $\mathrm{pH}$ was lower than 7.0 or higher than 7.8 These data reflected that the ionization of amino acid residues in the free enzyme influenced enzymatic activity and that $\mathrm{BChE}$ was a slightly basic esterase and worked in a narrow $\mathrm{pH}$ range. At the optimized $\mathrm{pH}$, we speculate that tertiary ammonium group 
of tetracine hydrochloride and of various active site ligands binds through a preferential interaction of quaternary nitrogens with the $\pi$ electrons of aromatic groups, the active site was called an anionic substrate-binding site composed of Trp82. In addition, the $\mathrm{pH}$ specificity of the enzyme was similar to that of basic aminopeptidase from Common carp (Umetsu et al., 2003), in which $\mathrm{pH}$ influenced the disruption of the spatial structure of enzymes and the dissociation constant between enzymes and substrates.

\section{Effect of incubation temperature on $\mathrm{BChE}$}

The BChE activities were measured at various temperatures. A series of aliquots of the $\mathrm{BChE}, 2.0 \mathrm{mM} \mathrm{Ca}^{2+}$ and $1.0 \mathrm{mM}$ tetracine hydrochloride substrate were incubated for $30 \mathrm{~min}$ at various temperatures. The results of this experiment were depicted in Fig. 4. The enzyme activity increased with the increasing temperature. However, at temperatures greater than optimal temperatures, the enzyme is denatured due to which enzyme activity is denatured. In our experiment, the activity of $\mathrm{BChE}$ increases over the range $20^{\circ} \mathrm{C}-50^{\circ} \mathrm{C}$ and revealed an optimum temperature at $50^{\circ} \mathrm{C}$. The activity declined obviously when the temperature increased further and came to its lowest peak at $70^{\circ} \mathrm{C}$. It is noteworthy that the enzyme retained $70 \%$ of its optimal activity at $37^{\circ} \mathrm{C}$, which is a suitable temperature for enzymatic activity.

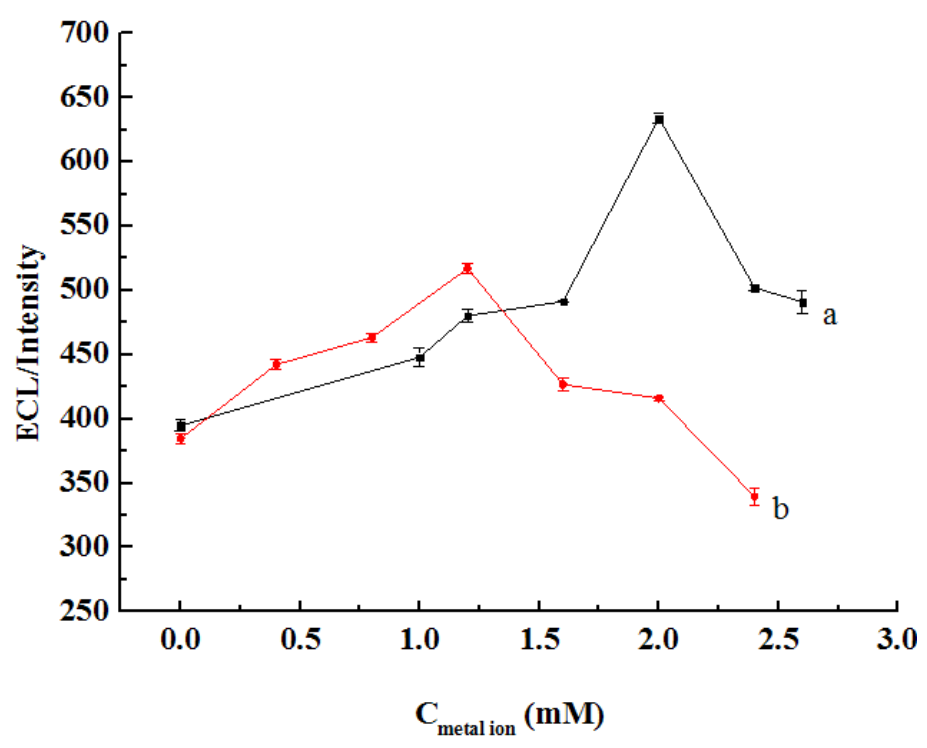

Fig. 2: Relationship between (ECL) intensity and concentration of $\mathrm{Ca}^{2+}$ (a) and $\mathrm{Mg}^{2+}$ (b). Conditions: $1.0 \mathrm{mM}$ tetracine hydrochloride in $30 \mathrm{mM}$ PBS at $\mathrm{pH} 7.5$; incubation at $37^{\circ} \mathrm{C}$ for $30 \mathrm{~min} ; 5.0 \mathrm{mM} \mathrm{Ru}(\mathrm{bpy})_{3}^{2+}$ in $80 \mathrm{mM}$ PBS at pH 7.0; detection potential, $1.2 \mathrm{~V}$ (vs Ag-AgCl).

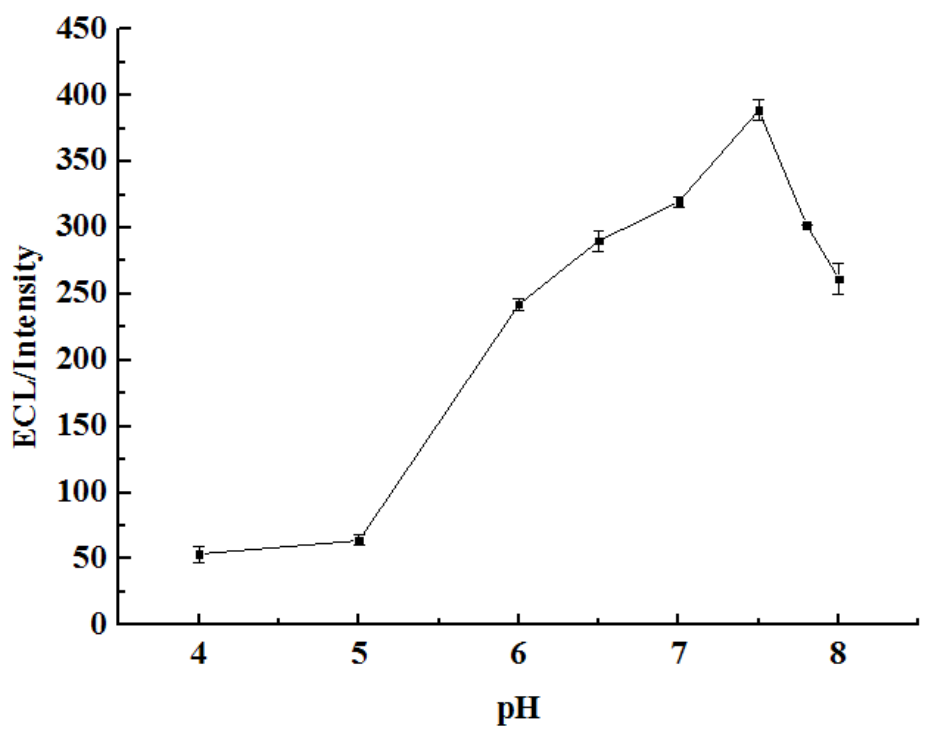

Fig. 3: Relationship between ECL intensity and $\mathrm{pH}$. Conditions: $1.0 \mathrm{mM}$ tetracine hydrochloride in $30 \mathrm{mM} \mathrm{PBS} ; 2.0 \mathrm{mM} \mathrm{Ca}^{2+}$; incubationat $37^{\circ} \mathrm{C}$ for $30 \mathrm{~min} ; 5.0 \mathrm{mM}$ $\mathrm{Ru}(\mathrm{bpy})_{3}{ }^{2+}$ in $80 \mathrm{mM}$ PBS at $\mathrm{pH} 7.0$; detection potential, $1.2 \mathrm{~V}(\mathrm{vs} \mathrm{Ag}-\mathrm{AgCl})$. 


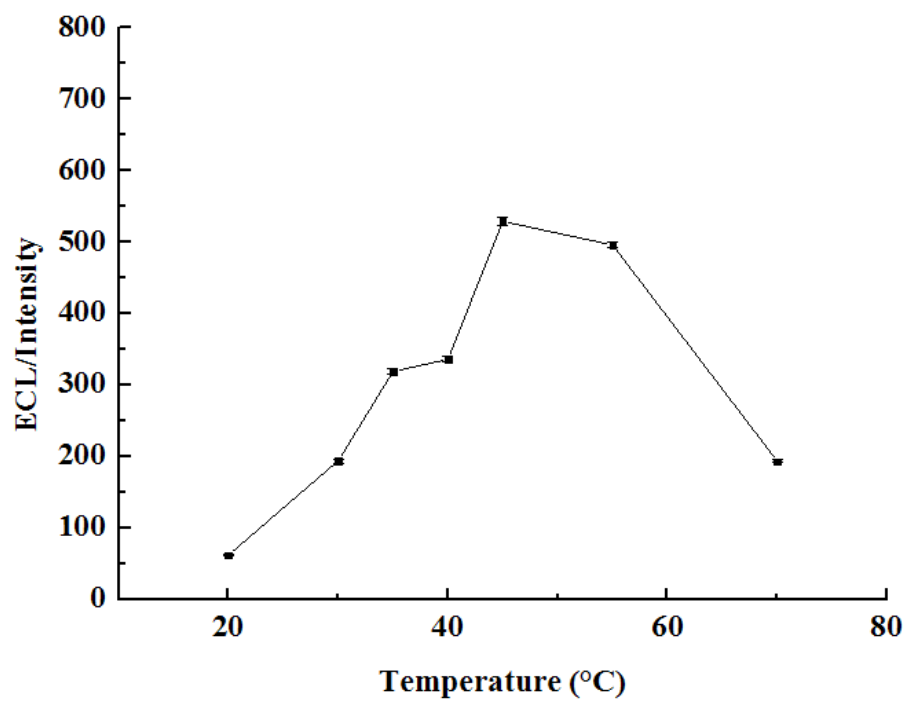

Fig. 4: Relationship between ECL intensity and temperature. Conditions: $1.0 \mathrm{mM}$ tetracine hydrochloride in $30 \mathrm{mM}$ PBS at pH 7.0; $2.0 \mathrm{mM} \mathrm{Ca}{ }^{2+}$; incubation time, 30 $\mathrm{min} ; 5.0 \mathrm{mM} \mathrm{Ru}(\mathrm{bpy})_{3}{ }^{2+}$ in $80 \mathrm{mM}$ PBS at $\mathrm{pH} 7.0$; detection potential, $1.2 \mathrm{~V}$ (vs Ag-AgCl).

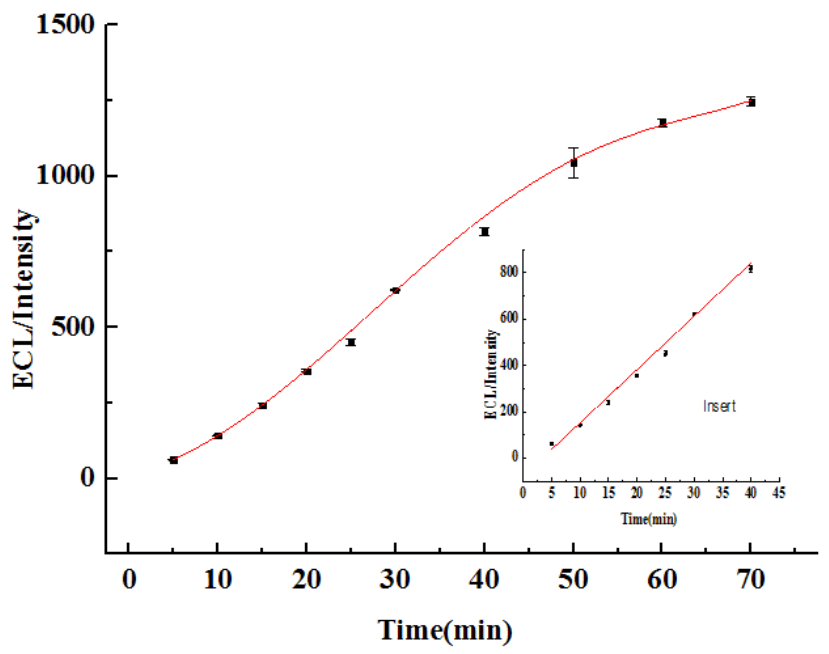

Fig. 5: Relationship between ECL intensity and incubation time within 70 and $40 \mathrm{~min}$ (inset). Conditions: $1.0 \mathrm{mM}$ tetracine hydrochloride in $30 \mathrm{mM}$ PBS at pH 7.5; 2.0 $\mathrm{mM} \mathrm{Ca}^{2+}$; incubation temperature, $37^{\circ} \mathrm{C} ; 5.0 \mathrm{mM} \mathrm{Ru}(\text { bpy })_{3}{ }^{2+}$ in $80 \mathrm{mM}$ PBS at $\mathrm{pH} 7.0$; detection potential, $1.2 \mathrm{~V}$ (vs Ag- $\mathrm{AgCl}$ ).

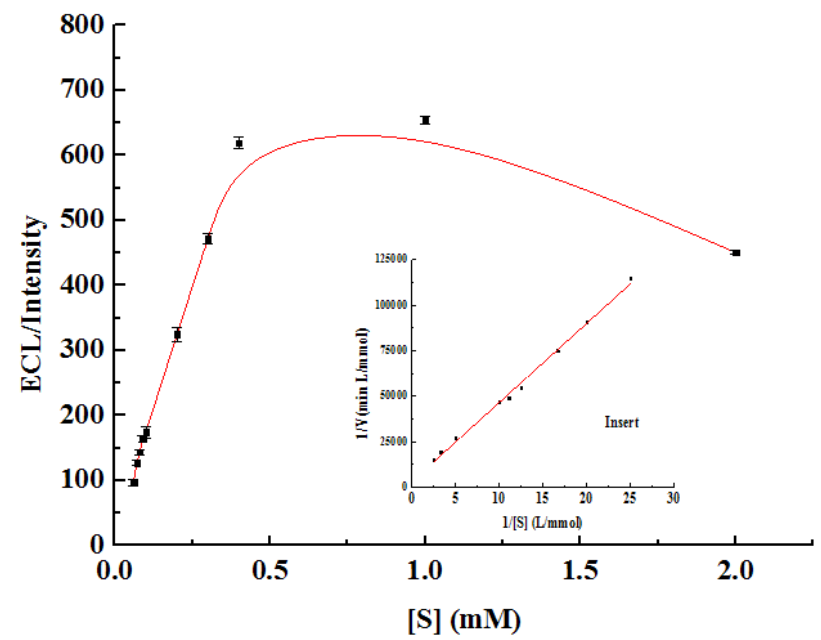

Fig. 6: The relationship between ECL intensity and substrate concentration. Inset: Lineweaver-Burk plot. Conditions: $1.0 \mathrm{mM}$ tetracine hydrochloride in $30 \mathrm{mM}$ PBS at $\mathrm{pH} 7.5 ; 2.0 \mathrm{mM} \mathrm{Ca}^{2+}$; incubation at $37^{\circ} \mathrm{C}$ for $30 \mathrm{~min} ; 5.0 \mathrm{mM} \mathrm{Ru}(\text { bpy })_{3}{ }^{2+}$ in $80 \mathrm{mM}$ PBS at pH 7.0; detection potential, $1.2 \mathrm{~V}$ (vs Ag- $\mathrm{AgCl}$ ). 


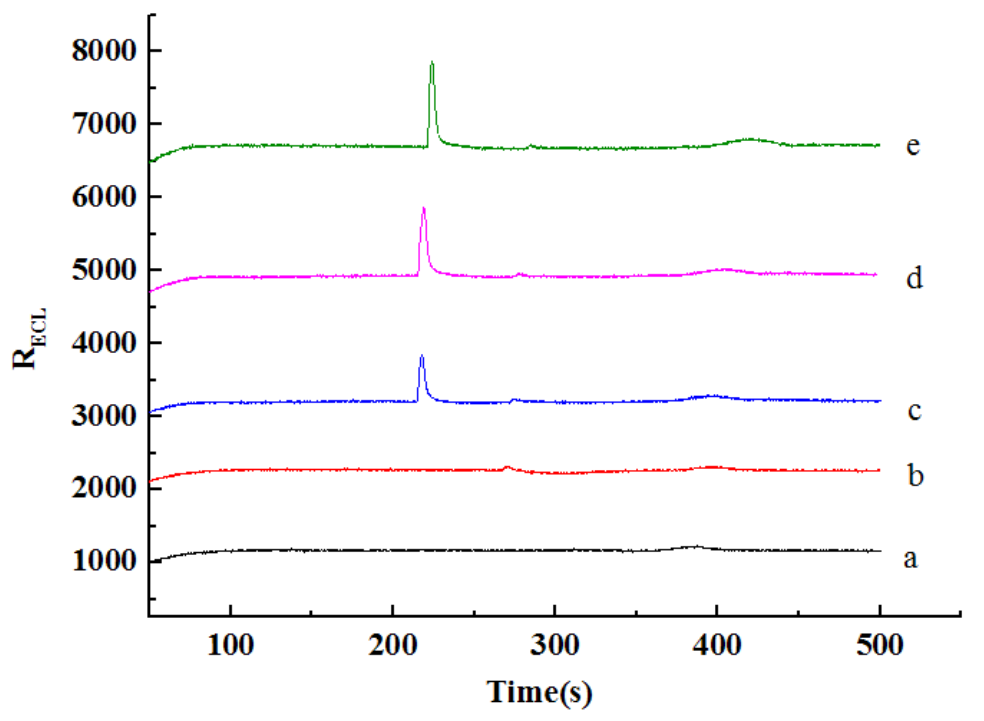

Fig. 7: Electropherograms of blank plasma without substrates (a); and plasma with addition of $1.0 \mathrm{mM}$ tetracine hydrochloride before inbubation (b); plasmas from liver cancer patients(c), cholestasis hepatitis patients (d), healthy people(e) with addition of $1.0 \mathrm{mM}$ tetracine hydrochloride after inbubation.

\section{Effect of incubation time on $\mathrm{BChE}$}

Fig. 5 showed the change of DMEA ECL signal with the increasing incubation time. The ECL intensity increased faster rate for the first $30 \mathrm{~min}$ and then the velocity declines gradually. This is consistent with the enzyme reaction kinetics. In order to accurately reflect the enzyme activity using initial velocity, the hydrolysis reaction should be terminated before the decline of enzymatic reaction velocity. As showed in inset in Fig. 5, BChE activity was linearly related to incubation time in the first 30 minutes. So, $30 \mathrm{~min}$ as the incubation time was chosen.

\section{Michaelis-Menten analysis}

The Michaelis-Menten plots which reflect the relationship between the initial velocity $(V)$ and substrate concentration ([S]) are presented in Fig. 6. The velocity of reaction increased quickly and was linear with increasing amounts of substrate at low substrate concentrations $(<1 \mathrm{mM})$, obeyed first-order reaction model, because the enzyme was not saturated by substrates at low level. The reaction rate reached a maximum value when the substrate concentration increased to $1.0 \mathrm{mM}$, which was consistent with zero order reaction. So, the maximum activity of BChE was obtained when the concentration of tetracine hydrochloride was $1 \mathrm{mM}$. For enzyme-catalyzed reactions, the relation between initial reaction velocity $(V)$ and substrate concentration $[S]$ can be described by the Michaelis-Menten equation:

$$
V=\frac{V_{\max }[S]}{K_{\mathrm{m}}+[S]}
$$

where $V_{\max }$ is the maximum reaction velocity and $K_{\mathrm{m}}$ is the Michaelis constant, which may be taken as the substrate concentration at half the maximum reaction velocity if the amount of product is negligible. The Lineweaver-Burk reciprocal equation is obtained by inversion of this equation, which describes a linear relation between $1 / V$ and $1 /[S]$.

$$
V=\frac{V_{\max }[S]}{K_{\mathrm{m}}+[S]}
$$

where $1 / V$ means the concentration of DMEA divided by the reaction time. Six different concentrations of tetracine hydrochloride incubated with the $\mathrm{BChE}$ for $30 \mathrm{~min}$, and then analyzed by CE-ECL. The Lineweaver-Burk plot lines for tetracine hydrochloride were shown in inset in Fig. 6 . The $K_{\mathrm{m}}$ and $V_{\max }$ value were calculated to be $1.16 \times 10^{-3} \mathrm{~mol} / \mathrm{L}$ and $2.71 \times 10^{-7}$ $\mathrm{mol} / \mathrm{L} / \mathrm{min}$, respectively.

\section{Application in evaluation plasma BChE activity}

The proposed method has been used for the determination of plasma $\mathrm{BChE}$ activity in cholestatic hepatitis and liver cancer patients. To detect BChE activity, diluted plasma samples and tetracine hydrochloride were reacted at $37^{\circ} \mathrm{C}$ for 30 min and then were injected into the capillary. Sample pretreatment such as dialysis or extraction was not necessary. Fig.7 showed the electropherograms of plasma in the presence of tetracine hydrochloride with or without incubation.

Firstly, we carried out a blank test. There was only plasma without addition of substrate in the blank test. As shown in electropherograms a, there was no ECL peak produced, indicating that no intrinsic species and anticoagulant interfered in the plasma BChE activity assay. Secondly, electropherogram b represented a control assay in which only substrate solution was added to plasma sample but without incubation. Finally, electrophoregrams $\mathrm{c}, \mathrm{d}$, and e represented assay for plasma samples from liver cancer, cholestasis hepatitis patients and healthy people, respectively, after incubation with $1.0 \mathrm{mM}$ tetracine hydrochloride under the optimal conditions. It was obvious that the DMEA content from healthy plasma was much higher than that from the diseased plasma, indicating that the activity of BChE had a great change for patients caught liver disease, especially in liver cancer patients. 
Table 1: Results of BChE activities detected by CE-ECL and clinical method.

\begin{tabular}{|c|c|c|c|c|}
\hline Pathogeny & $\begin{array}{l}\text { Sample } \\
\text { (No) }\end{array}$ & $\begin{array}{c}\text { CE-ECL } \\
\operatorname{method}(U / L)\end{array}$ & $\begin{array}{c}\text { Clinical method } \\
(\mathrm{U} / \mathrm{L})\end{array}$ & $\begin{array}{c}\text { (CE-ECL } \\
\text { method-Clinical } \\
\text { method)/Clinical } \\
\text { method) }\end{array}$ \\
\hline \multirow[t]{10}{*}{ Liver cancer } & 1 & 3257 & 3453 & $-5.68 \%$ \\
\hline & 2 & 3350 & 3485 & $-3.87 \%$ \\
\hline & 3 & 3856 & 3687 & $4.58 \%$ \\
\hline & 4 & 3150 & 3315 & $-4.98 \%$ \\
\hline & 5 & 3589 & 3425 & $-4.80 \%$ \\
\hline & 6 & 4105 & 4312 & $-4.80 \%$ \\
\hline & 7 & 3875 & 3698 & $4.79 \%$ \\
\hline & 8 & 3683 & 3565 & $3.31 \%$ \\
\hline & 9 & 3323 & 3463 & $4.04 \%$ \\
\hline & 10 & 3415 & 3569 & $4.31 \%$ \\
\hline \multirow[t]{10}{*}{$\begin{array}{l}\text { Cholestasis } \\
\text { hepatitis }\end{array}$} & 1 & 5263 & 5389 & $-2.34 \%$ \\
\hline & 2 & 5845 & 6012 & $-2.78 \%$ \\
\hline & 3 & 5135 & 5325 & $-3.57 \%$ \\
\hline & 4 & 5216 & 5020 & $3.90 \%$ \\
\hline & 5 & 5985 & 5760 & $3.91 \%$ \\
\hline & 6 & 6158 & 6435 & $-4.30 \%$ \\
\hline & 7 & 5945 & 6124 & $-2.92 \%$ \\
\hline & 8 & 6210 & 6547 & $-5.15 \%$ \\
\hline & 9 & 5673 & 5400 & $5.06 \%$ \\
\hline & 10 & 5286 & 5486 & $-3.65 \%$ \\
\hline \multirow[t]{5}{*}{$\begin{array}{l}\text { Normal } \\
\text { control }\end{array}$} & 1 & 7218 & 7563 & $-4.56 \%$ \\
\hline & 2 & 7536 & 7789 & $-3.25 \%$ \\
\hline & 3 & 7680 & 7415 & $3.57 \%$ \\
\hline & 4 & 7510 & 7686 & $-2.29 \%$ \\
\hline & 5 & 7376 & 6970 & $5.82 \%$ \\
\hline
\end{tabular}

Table 2: Plasma leucyl aminopeptidase activity in patients with liver diseases.

\begin{tabular}{lcccc}
\hline Group & n & $\begin{array}{c}\text { BChE activity } \\
\text { (U/L) }\end{array}$ & $\begin{array}{c}\text { Number of } \\
\text { positive }\end{array}$ & $\begin{array}{c}\text { Positive rate } \\
\text { (\%) }\end{array}$ \\
\hline Liver cancer & 26 & $3865.44 \pm 135$ & 19 & $73.08 \%$ \\
Cholestasis hepatitis & 23 & $5982 \pm 225$ & 16 & $69.57 \%$ \\
Normal control & 5 & $7464 \pm 156$ & -- & -- \\
\hline
\end{tabular}

The activity of BChE in plasma of 5 normal subjects, 10 cholestasis hepatitis patients, and 10 liver cancer patients were determined and the results were listed in Table 1. It was demonstrated that plasma BChE activity from hepatopaths was much lower than that from healthy people. This is mainly due to the degrees of degeneration and necrosis for liver. The more serious liver tissue damaged, lower the activity of the enzyme. Especially, plasma $\mathrm{BChE}$ activity from liver cancer patients was much lower than that from cholestasis hepatitis patients. These results were in good agreement with that from clinical method based on spectral absorption. The errors were from $-5.68 \%$ to $5.82 \%$. The correlation between enzyme activity and liver injury is accordance with the previous report (Carello et al., 1999). All these results indicated that the proposed method for BChE activity determination was accurate and reliable.
These results were calculated by statistical analysis. It is assumed that the two-tailed $\mathrm{p}$ values were significantly $<0.05$, plasma BChE activity (mean $\pm \mathrm{SD}$ ) in the groups was shown in table 2. Mean $\pm \mathrm{SD}$ were $3865.44 \pm 135 \mathrm{U} / \mathrm{L}$ for twenty-six liver cancer plasma samples and $5982 \pm 225 \mathrm{U} / \mathrm{L}$ for twenty-three cholestasis hepatitis plasma samples respectively. All the obtained data were much lower than the normal reference interval $7464 \pm$ $156 \mathrm{U} / \mathrm{L}$. There was also a significant positive correlation between elevated BChE activity in plasmas and liver lesion diseases. The positive rate was $73.08 \%$ in twenty-six plasma samples for liver cancer and $69.57 \%$ in twenty-three plasma samples for cholestasis hepatitis.

\section{CONCLUSION}

In this study, the CE coupled with ECL detection was used to investigate the $\mathrm{BChE}$ activity for diagnosis of liver disease. The kinetic study of enzymatic-catalyzed tetracine hydrochloride hydrolysis was investigated and both $K_{\mathrm{m}}$ and $V_{\max }$ value of enzymatic reaction were determined. The low detection limit, wide linear range, and good reproducibility for the indirect detection of DMEA made it become a suitable signal probe for enzyme analysis. More importantly, the experimental process is simple and environmental friendly since this method does not use the chromogenic reagents with poor chemical stability, enormous toxicity, and carcinogenicity which are typically used in the clinical analysis method. The proposed method has been successfully applied to detect BChE activity in the clinical plasma samples. Results demonstrated that a highly significant increase in $\mathrm{BChE}$ activity in liver diseases patients, which agreed well with the results detected by clinical method.

\section{ACKNOWLEDGEMENTS}

The project is supported by Natural Science Foundation of Hebei Province (B2015201193), Science and Technology Research Project of Hebei Higher Education (QN2016087), Science and Technology Research Program of Baoding City (16ZF190), Graduate Student Research and Innovation Program of Jiangsu Province (CX10B_068Z).

\section{CONFLICT OF INTEREST}

The authors declare that they have no conflict of interest.

\section{REFERENCES}

Ashani Y. Prospective of human butyrylcholinesterase as a detoxifying antidote and potential regulator of controlled-release drugs. Drug Dev Res. 2000; 50:298-308.

Auld DS. Metalloproteases in Encyclopedia of Biological Chemistry. Elsevier: Amsterdam. 2004; 2:652-656.

Brimijoin S, Hammond P. Butyrylcholinesterase in human brain and acetylcholinesterase in human plasma: trace enzymes measured by twosite immunoassay. J Neurochem. 1988; 51:1227-31.

Buetis CA, Ashwood ER. Tietz textbook of clinical chemistry. 3rd ed. Philadephia:W. B. Saunders Company, 1999: 940.

Blanloeil Y, Delaroche O. Decrease in plasmatic cholinesterase activity in severe bacterial infections: comparison with the decrease observed in severe liver cirrhosis.Ann Fr Anesth Reanim. 1996; 15:220 222 .

Carmona GN, Jufer RA, Goldberg SR, Gorelick DA, Greig NH, Yu QS, Cone EJ, Schindler CW. Butyrylcholinesterase accelerates cocaine metabolism: in vitro and in vivo effects in nonhuman primates and humans. 
Drug Metab Dispos. 2000; 28:367-371.

Carello E, Rattisla S, Bar F, Niro GA, Cappello N, Rizzetto M, Molino G. Evaluation of hepatic function in liver cirrhosis clinical utility of galactose elimination capacity hepatic clearance of D-sorbitol and laboratory investigation. Dig Dis Sci. 1999; 44:782-788.

Deng BY, Ye L, Yin HH, Liu Y, Hu SY, Li BF. Determination of pseudolycorine in the bulb of lycoris radiata by capillary electrophoresis combined with online electrochemiluminescence using ultrasonicassisted extraction. J Chromatogr B. 2011; 879:927-932.

Ellman GL, Courtney KD, Jr. VA, FeatherStone RM. A new and rapid colorimetric determination of acetylcholinesterase activity. Biochem Pharmacol. 1961;7:88-95.

Gorelick DA. Enhancing cocaine metabolism with butyrylcholinesterase as a treatment strategy. Drug Alcohol Depen. 1997; 48:159-165.

Gómez JL, García-Ayllón MS, Campoy FJ, Vidal CJ. Muscular dystrophy alters the processing of light acetylcholinesterase but not butyrylcholinesterase forms in liver of Lama ${ }^{\mathrm{dy}}$ mice. J Neurosci Res. 2000; 62:134-145.

Fogle EJ, Marlier JF, Stillman A,Gao X, Rao Y, Robins LI. An investigation into the butyrylcholinesterase-catalyzed hydrolysis of formylthiocholine using heavy atom kinetic isotope effects. Bioorg Chem. 2016; 65:57-60.

Johnson G, Moore SW. Why has butyrylcholinesterase been retained? Structural and functional diversification in a duplicated gene. Neurochem Int. 2012; 61:783-797.

Lynch TJ, Mattes CE, Singh A, Bradley RM, Brady RO, Dretchen KL. Cocaine detoxification by human plasma butyrylcholinesterase. Toxicol Appl Pharmacol. 1997; 145:363-371.

Lucić VA, Bradamante V, Radić B, Peraica M, Fuchs R, Reiner Z. Butyrylcholinesterase activity and plasma lipids in dexamethasone treated rats. Acta Pharm. 2005; 55:177-185.

Li T, Yuan JP, Yin JY, Zhang ZW, Wang EK. Capillary electrophoresis with electrochemiluminescence detection for measurement of aspartate aminotransferase and alanine aminotransferase activities in biofluids. J Chromatogr A. 2006; 1134:311-316.

Li M, Lee SH. Determination of trimethylamine in fish by capillary electrophoresis with electrogenerated tris(2,2'-bipyridyl) ruthenium(II) chemiluminescence detection. Luminescence. 2007; 22:588593.

Liu YM, Shi YM, Liu ZL. Determination of enoxacin and ofloxacin by capillary electrophoresis with electrochemiluminescence detection in biofluids and drugs and its application to pharmacokinetics. Biomed Chromatogr. 2010; 24:941-947.

Manoharan I, Kuznetsova A, Fisk JD, Boopathy R, Lockridge O, Darvesh S. Comparison of cognitive functions between people with silent and wild-type butyrylcholinesterase. J Neural Transm. 2007; 114:939-45.

Peters J, Trovaslet M, Trapp M, Nachon F, Hill F, Royer E, Gabel F, van Eijck L, Masson P, Tehei M. Activity and molecular dynamics relationship within the family of human cholinesterases. Phys Chem Chem Phys. 2012; 14:6764-6770.
Saxena A, Redman AM, Jiang X, Lockridge O, Doctor BP. Differences in active site gorge dimensions of cholinesterases revealed by binding of inhibitors to human butyrylcholinesterase. Biochem. 1997; 36:14642-14651.

Sreedhar M, Lin YW, Tseng WL, Chang HT. Determination of tertiary amines based on $\mathrm{pH}$ junctions and field amplification in capillary electrophoresis with electrochemiluminescence detection. Electrophoresis. 2005; 26:2984-2990.

Su M, Win M, Zhou ZX, Liu SQ. Application of capillary electrophoresis coupling with electrochemiluminescence detection to estimate activity of leucine aminopeptidas. Biomed Chromatogr. 2013; 27:946-952.

Tvarijonaviciute A, Ceron JJ, Tecles F. Acetylcholinesterase and butyrylcholinesterase activities in obese Beagle dogs before and after weight loss. Vet Clin Path. 2013; 42:207-211.

Wang YC, Wu Q, Cheng MR, Cai C. Determination of b-blockers in pharmaceutical and human urine by capillary electrophoresis with electrochemiluminescence detection and studies on the pharmacokinetics. J Chromatogr B. 2011; 879:871-877.

Umetsu H, Arai M, Ota T, Kudo R, Sugiura H, Ishiyama H, Sasaki K. Purification and properties of an aminopeptidase from the midgut gland of scallop (Patinopecten yessoensis). Comp Biochem Phys B. $2003 ; 136: 935-942$

Waiskopf N, Shweky I, Lieberman I, Banin U, Soreq H.Quantum dot labeling of butyrylcholinesterase maintains substrate and inhibitor interactions and cell adherence features. ACS Chem Neurosci. 2011; 2:141150

Yuan JP, Li T, Yin XB, Guo L, Jiang XZ, Jin WR, Yang XR, Wang EK. Characterization of prolidase activity using capillary electrophoresis with tris(2,2'-bipyridyl)ruthenium(II) electrochemiluminescence detection and application to evaluate collagen degradation in diabetes mellitus. Anal Chem 2006; 78: 2934-2938.

Yuan JP, Yin JY, Wang EK. Characterization of procaine metabolism as probe for the butyrylcholinesterase enzyme investigation by simultaneous determination of procaine and its metabolite using capillary electrophoresis with electrochemiluminescence detection. J Chromatogr A. 2007; 1154:368-372.

Yuan BQ, Zheng CY, Teng H, You T. Simultaneous determination of atropine, anisodamine, and scopolamine in plant extract by nonaqueous capillary electrophoresis coupled with electrochemiluminescence and electrochemistry dual detection. J Chromatogr A. 2010; 1217:171-174.

How to cite this article:

Wang D, Li F, Su M, Sun H. Application of capillary electrophoresis coupling with electrochemiluminescence detection to estimate activity of butyrylcholinesterase. J App Pharm Sci, 2018; 8(04): 007-014. 